Article

\title{
Investigating the Role of MicroRNA and Transcription Factor Co-regulatory Networks in Multiple Sclerosis Pathogenesis
}

\author{
Nicoletta Nuzziello ${ }^{1}$, Laura Vilardo $^{2}$, Paride Pelucchi ${ }^{2}{ }^{\circledR}$, Arianna Consiglio ${ }^{1}{ }^{(D)}$, \\ Sabino Liuni ${ }^{1}$, Maria Trojano ${ }^{3}$ and Maria Liguori ${ }^{1}$ * (1) \\ 1 National Research Council, Institute of Biomedical Technologies, Bari Unit, 70126 Bari, Italy; \\ nicoletta.nuzziello@gmail.com (N.N.); ariannaconsiglio@gmail.com (A.C.); sabino.liuni@ba.itb.cnr.it (S.L.) \\ 2 National Research Council, Institute of Biomedical Technologies, Segrate Unit, 20090 Milan, Italy; \\ laura.vilardo@itb.cnr.it (L.V.); paride.pelucchi@itb.cnr.it (P.P.) \\ 3 Department of Basic Sciences, Neurosciences and Sense Organs, University of Bari, 70124 Bari, Italy; \\ maria.trojano@uniba.it \\ * Correspondence: maria.liguori@cnr.it or maria.liguori@ba.itb.cnr.it; Tel.: +39-080-5929663; \\ Fax: +39-080-5929690
}

Received: 31 October 2018; Accepted: 16 November 2018; Published: 20 November 2018

\begin{abstract}
MicroRNAs (miRNAs) and transcription factors (TFs) play key roles in complex multifactorial diseases like multiple sclerosis (MS). Starting from the miRNomic profile previously associated with a cohort of pediatric MS (PedMS) patients, we applied a combined molecular and computational approach in order to verify published data in patients with adult-onset MS (AOMS). Six out of the 13 selected miRNAs (miR-320a, miR-125a-5p, miR-652-3p, miR-185-5p, miR-942-5p, miR-25-3p) were significantly upregulated in PedMS and AOMS patients, suggesting that they may be considered circulating biomarkers distinctive of the disease independently from age. A computational and unbiased miRNA-based screening of target genes not necessarily associated to MS was then performed in order to provide an extensive view of the genetic mechanisms underlying the disease. A comprehensive MS-specific miRNA-TF co-regulatory network was hypothesized; among others, SP1, RELA, NF-KB, TP53, AR, MYC, HDAC1, and STAT3 regulated the transcription of 61 targets. Interestingly, NF- $\mathrm{KB}$ and STAT3 cooperatively regulate the expression of immune response genes and control the cross-talk between inflammatory and immune cells. Further functional analysis will be performed on the identified critical hubs. Above all, in our view, this approach supports the need of multidisciplinary strategies for shedding light into the pathogenesis of MS.
\end{abstract}

Keywords: Multiple Sclerosis; miRNAs; transcription factors; target genes; bioinformatics; circulating biomarkers; pathogenesis

\section{Introduction}

In humans, as in other species, the gene regulation process assumes multiple modes, including transcriptional regulation played by the regulatory proteins or transcription factors (TFs), and post-transcriptional regulation by including, most notably, microRNAs (miRNAs). MiRNAs are a class of highly conserved and single-stranded small non-coding RNAs that regulate gene expression by repressing specific target genes at the post-transcriptional level [1]. The miRNA repository miRBase (Release 22) [2] currently lists 1917 precursor miRNAs and 2654 mature miRNAs in the human genome; multiple or a cluster of miRNAs cooperatively regulate a given target gene leading to complex regulatory networks $[3,4]$, and multiple genes can be targeted by the same miRNA. Taken together, 
these findings indicate that the relationships between miRNAs and their targets are not one-to-one, but multiple-to-multiple [5].

Besides miRNAs, TFs participate in the regulatory network that controls the expression of thousands mammalian genes by binding their promoter region at transcriptional level [6]. TFs and miRNAs are two key regulators that control their own expression and the expression of their mutual targets by feedback loop (FBL) and feed-forward loop (FFL) modalities [7]. FFLs can be distinguished into three types according to the master regulator: TF-FFL, miRNA-FFL, and composite FFL [8-10]. Recently, miRNA/TF-based FFLs have been reported to act as a major member of biological network motifs in complex multifactorial diseases like Multiple Sclerosis (MS) [11,12].

MS is a chronic inflammatory demyelinating and neurodegenerative disease of the Central Nervous System (CNS) [13] in which genetic, epigenetic, and environmental factors possibly contribute to its susceptibility and/or outcomes [14]. The disease onset typically occurs in young adults, especially females, although diagnosis during childhood and adolescence has been increasingly recognized worldwide, accounting for $3-10 \%$ of the whole MS population, hence called pediatric MS (PedMS) [15-17].

Given the complex heterogeneity of MS [18], the possibility to identify reliable markers, i.e., predictive of the clinical course or response to treatments, has so far been elusive due to its multifactorial nature that involves several genes and their interactions. To pursue this issue, in a previous study [19] we investigated the transcriptome profile of peripheral blood samples in a cohort of PedMS patients, and we found that 12 mature miRNAs were significantly upregulated (let-7a-5p, let-7b-5p, miR-25-3p, miR-125a-5p, miR-942-5p, miR-221-3p, miR-652-3p, miR-182-5p, miR-185-5p, miR-181a-5p, miR-320a, and miR-99b-5p) and one miRNA was downregulated (miR-148b-3p) in PedMS patients compared to pediatric control (PC) subjects.

In the present evaluation, we analysed the expression pattern of the 13 identified miRNAs in an adult MS group from the same geographic area in order to verify whether the reported miRNomic profile was a peculiar signature of the "environmentally naïve" PedMS rather than a common feature of the general MS condition.

Based on the obtained results and according to the transcriptional regulatory rule, a comprehensive MS-specific miRNA-TF co-regulatory network was then built, suggesting an alternative and valuable approach for the identification of significant regulators and their target genes in MS.

\section{Results}

The study population consisted of 58 MS patients with adult onset of the disease (AOMS) and 20 age-matched healthy control (HC) subjects; Table 1 shows their demographic and clinical features.

Table 1. Summary of the demographic and clinical features of the study population.

\begin{tabular}{ccc}
\hline & AOMS (no. 58) & HC (no. 20) \\
\hline Female/Male Ratio & 2.7 & 2.3 \\
\hline Age (y, mean \pm SD) & $37.8 \pm 11.3$ & $43.2 \pm 3.1$ \\
\hline Age at MS Onset (y, mean \pm SD) & $34.3 \pm 9.6$ & \\
\hline MS Course (RR/SP/PP) & $54 / 4 / 0$ \\
\hline Disease Duration (y, mean \pm SD) & $13.4 \pm 9.3$ \\
\hline EDSS Score & $2.7 \pm 1.1$ \\
\hline DMT (y/n) & $56 / 2$ \\
\hline
\end{tabular}

AOMS = Adult-Onset Multiple Sclerosis; HC = healthy control; DMT = disease modifying treatment. 


\subsection{MicroRNA Differential Expression in AOMS}

The 13 miRNAs that were differentially expressed (DE) in PedMS (details in Reference [19]) were analysed by a microfluidic qPCR approach in the AOMS patients. A normalization of each miRNA expression level was performed using the recommended reference miRNAs (miR-191-5p and miR-103a-3p), as suggested from the qPCR study [19-21], and from candidate miRNA endogenous controls in the TaqMan Advanced miRNA Assay white paper (Applied Biosystems, Thermo Fisher Scientific). Six miRNAs (miR-320a, miR-125a-5p, miR-652-3p, miR-185-5p, miR-942-5p, and miR-25-3p) were confirmed to be significantly DE in AOMS patients compared with HCs (Figure 1). In detail, results from the qPCR analysis showed statistically significant upregulation of miR-320a ( $\mathrm{FC}=1.79$; $p$-value $\left.=1.8 \times 10^{-3}\right)$, miR-125a-5p $\left(\right.$ Fold Change $\mathrm{FC}=1.89 ; p$-value $\left.=5.9 \times 10^{-3}\right)$, miR-652-3p $\left(\mathrm{FC}=1.51 ; p\right.$-value $\left.=7.8 \times 10^{-3}\right)$, miR-185-5p $\left(\mathrm{FC}=1.5 ; p\right.$-value $\left.=8 \times 10^{-3}\right)$, miR-942-5p $(\mathrm{FC}=1.67 ;$ $p$-value $\left.=8.3 \times 10^{-3}\right)$ and miR-25-3p $\left(\mathrm{FC}=1.49 ; p\right.$-value $\left.=1.2 \times 10^{-2}\right)$ in AOMS patients compared to HCs.

\section{Volcano plot}

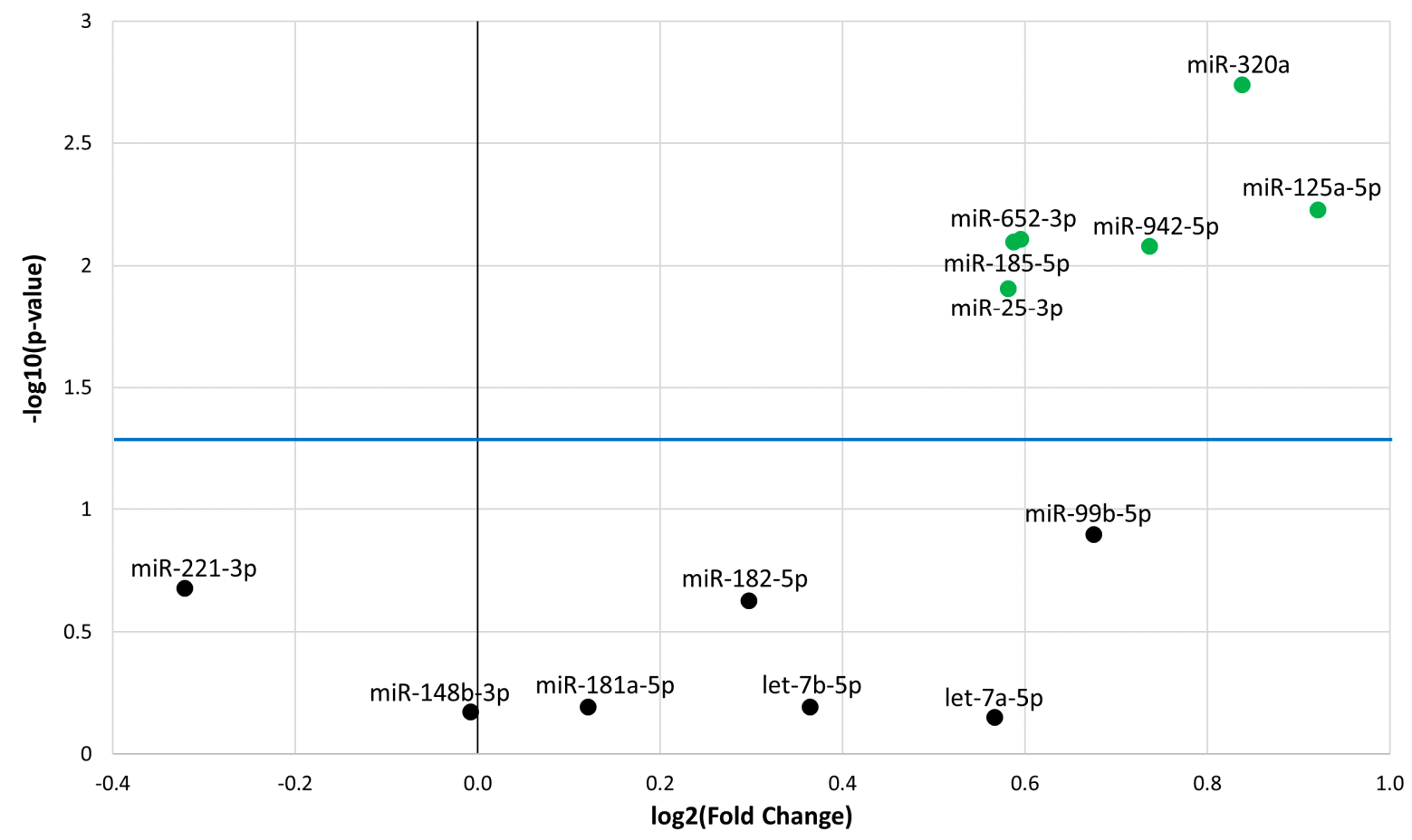

Figure 1. Volcano plot of the 13 microRNAs (miRNAs). The differentially expressed miRNAs with $p<0.05$ are shown as green dots. All dots (black) under the blue line did not discriminate Multiple Sclerosis (MS) from healthy controls (HC). The Y-axis represents $-\log 10$ of the $p$-value and the X-axis represents $\log 2$ fold change of miRNA expression in the MS versus HC.

A receiver operating characteristic (ROC) curve was generated for each validated miRNA, and the area under the curve (AUC) was calculated (Figure 2). MiR-320a, miR-185-5p, miR-125a-5p, and miR-652-3p provided AUC in a range from 0.701 to 0.735 ( $p$-value $\left.\leq 2 \times 10^{-3}\right)$, discriminating AOMS patients from HCs; miR-320a provided the best AUC $\left(0.735 ; p\right.$-value $\left.=1 \times 10^{-4}\right)$. 

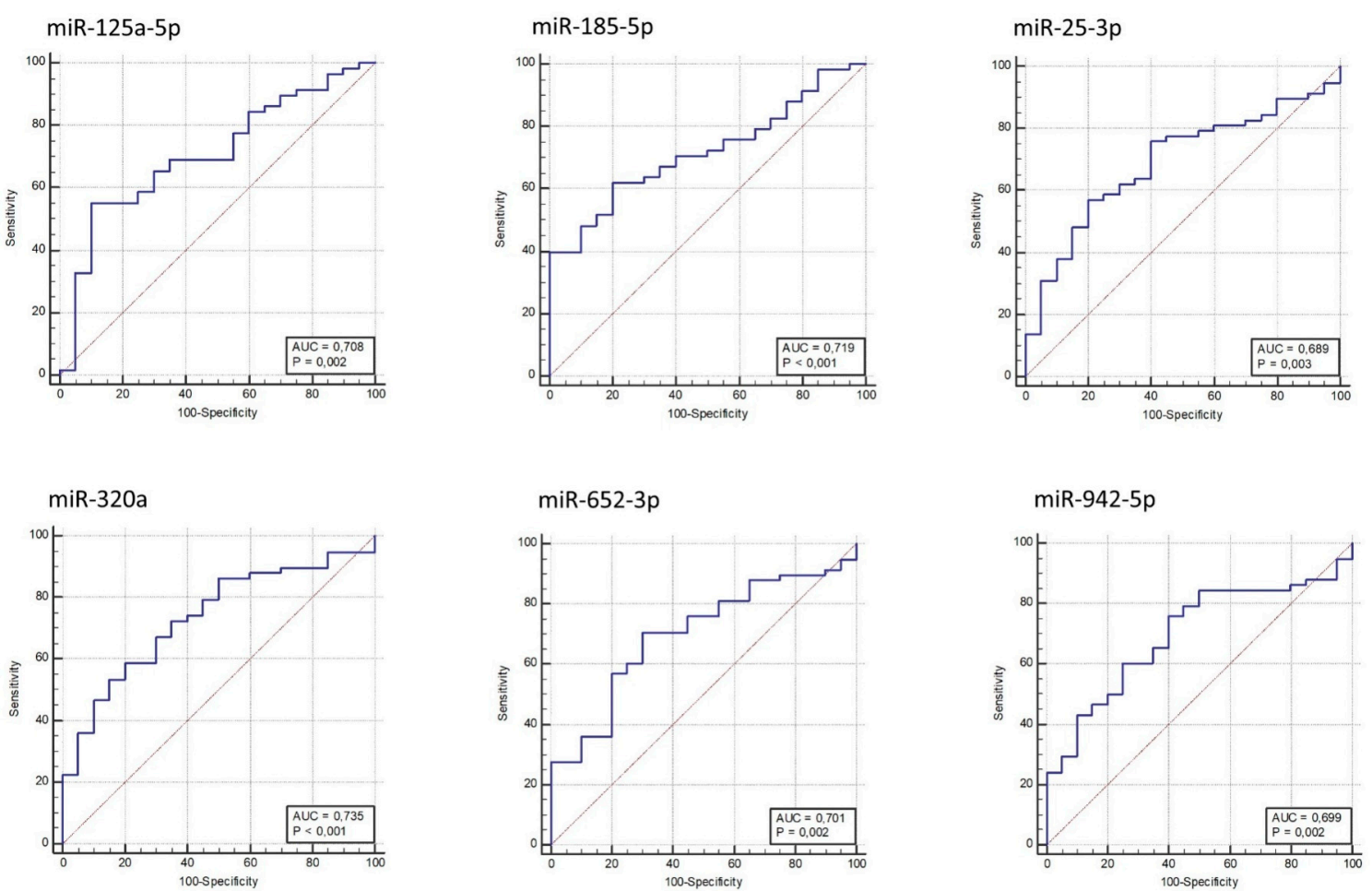

Figure 2. Receiver operating characteristic (ROC) curves for MS versus HC based on miRNAs relative expression data. The diagram is a plot of sensitivity (true-positive rate) versus specificity (false-positive rate).

\subsection{MicroRNA Target Analysis}

The identification of genes targeted by each miRNA is an important first step in elucidating its function(s). For this purpose, we determined the validated and predicted protein-coding gene targets of the six abovementioned DE miRNAs. Using databases containing experimentally validated miRNA-target interactions (miRtarbase and DIANA-Tarbase; see the Materials and Methods section), 155 miRNA-target pairs were validated by reporter gene assays. Since the prediction of the target site of existing algorithms can still be characterized by low precision and poor sensitivity, according to published guidelines [22], we integrated the predictions of different algorithms in order to combine their results. To this end, we uncovered 513 miRNA-target pairs predicted in at least four out of the five miRNA-target interaction tools (miRanda, RNA22, mirDB, TargetScan, DIANA-microT-CDS). Thirty miRNA-target pairs were found overlapping between the validated and predicted miRNA-target interactions.

We therefore constructed the miRNA-based network, including the DE miRNAs and their associated targets that fulfilled the selection criteria (Figure 3), using Cytoscape v3.6.0 [23]. The miRNA-target gene network consisted of 616 nodes (4 miRNAs and 612 miRNA targets) and 638 directed edges that resulted from miRNA-target interactions and were predicted by at least four algorithms and/or validated by reporter gene assays. Interestingly, several target genes (TP53, SLC4A10, CDKN1A, ERBB2, ATRX, ST6GAL2, PTEN, FAM160B1, SMAD7, IKZF4, PHLPP2, MCL1, KCNS3, NFATC3, AR, IGF1R, PCDHA4, TANC2, ZNF704, WWC2, NTRK3, NCAN, VEGFA, MSI1, LCOR, and RBM20) were shared by two of the following miRNAs: miR-125a-5p, miR-320a, miR-25-3p, and miR-185-5p. The remaining miR-942-5p and miR-652-3p were not enclosed in the network loop reported in Figure 3, as they did not share any target genes with the remaining miRNAs. 


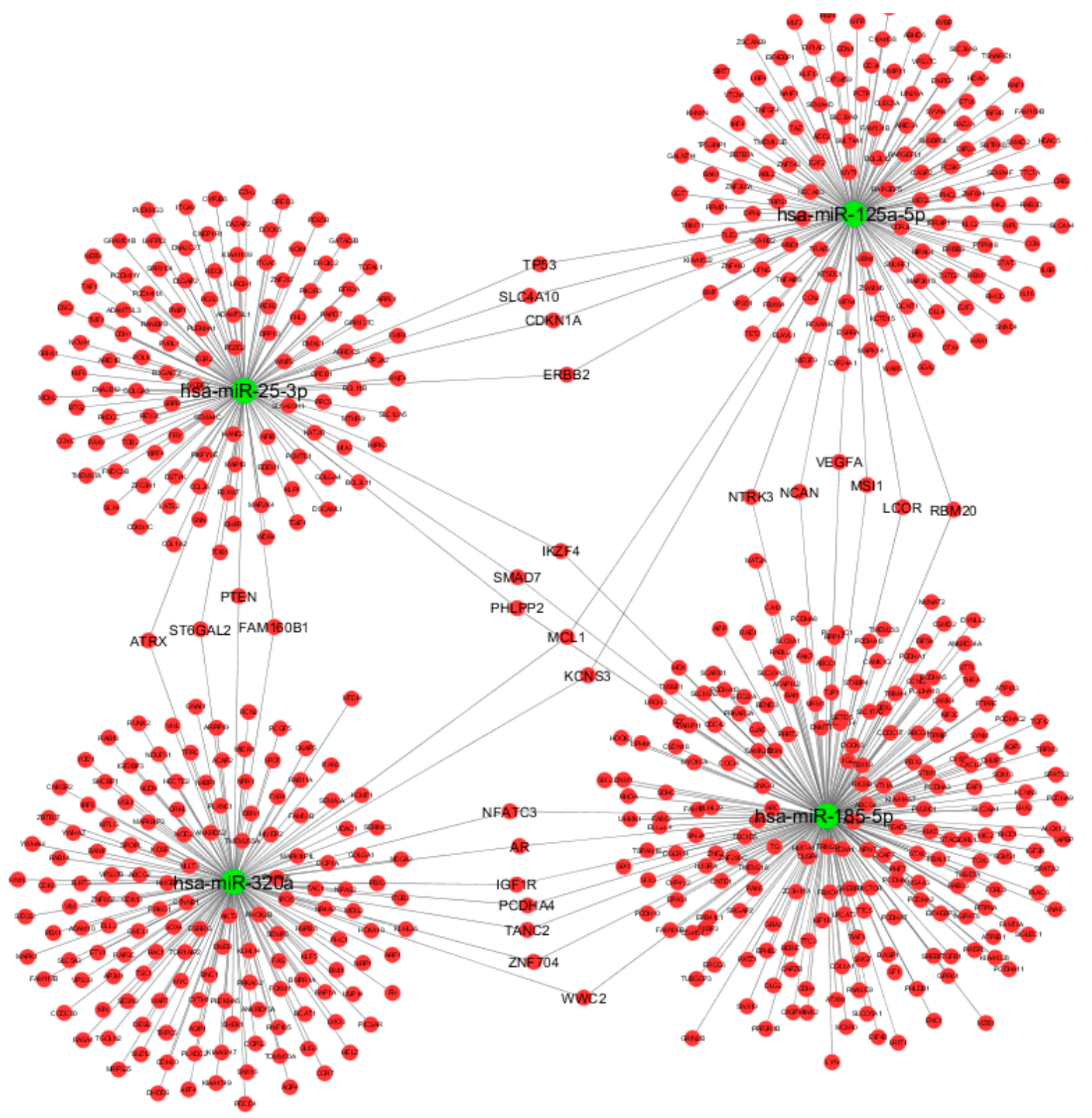

Figure 3. Graphical representation of computationally predicted/validated miRNA-target interactions using Cytoscape v3.6.0. Green nodes represent miRNAs, red nodes represent target genes. We excluded miR-942-5p and miR-652-3p miRNAs since our main purpose was to show the miRNA-based network.

\section{3. miRNA-TF Co-regulatory Network}

The TFs that regulate the six significantly DE miRNAs and their targets were identified. TF-miRNA interactions were exported from the Harmonizome [24] repository and combined with information on interactions from the TransmiR database [6]. We identified 409 TF-miRNA interactions (Figure 4); notably, MAX, MYC, TCF3, and SREBF1 were in common to all the six DE miRNAs. 


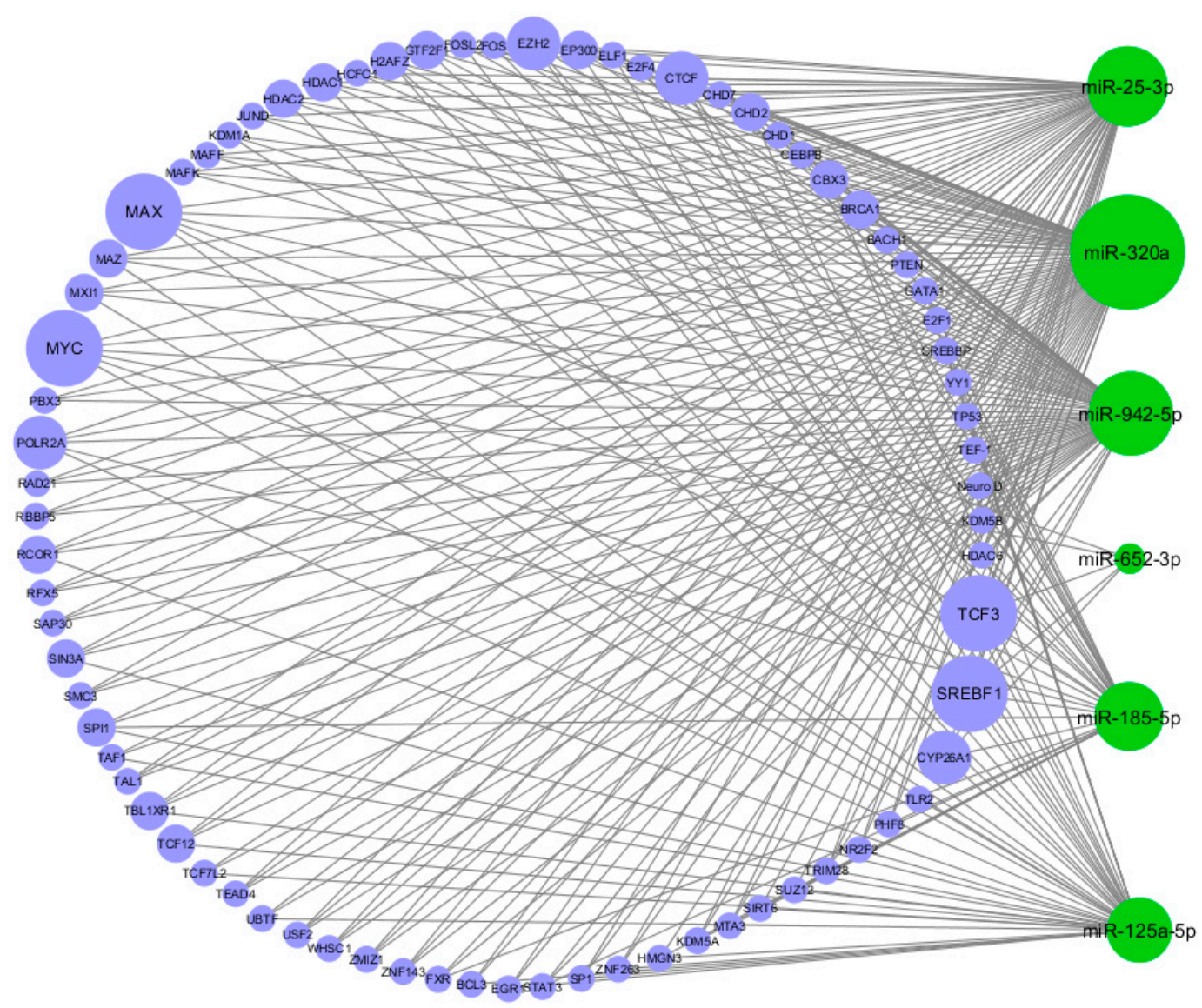

Figure 4. Circular view of transcription factor-miRNA (TF-miRNA) interactions. Green nodes represent the miRNAs, blue nodes represent the TFs. The size of the nodes is proportional to the degree of the nodes (number of incoming and outcoming edges). As shown in the figure, the four biggest TF nodes are MAX, MYC, TCF3, and SREBF1.

We also identified eight miRNA-TF feedback loops (FBLs) that included TP53, SREBF1, EZH2, FOXM1, MYC, ZBTB7A, SUZ12, miR-125a-5p, miR-185-5p, and miR-320a (Table 2). 
Table 2. List of significantly upregulated miRNAs in the comparison between MS and HC. For each miRNA, the log2 fold change and $p$-value from qPCR analysis have been detailed. The ROC section shows the results of AUC and associated $p$-value. The total number of miRNA targets and TFs that regulate each miRNA has been indicated. In the last section (miRNA-TF co-regulatory networks), we listed the total number of networks in which the studied miRNAs seem to be involved.

\begin{tabular}{|c|c|c|c|c|c|c|c|c|c|c|}
\hline \multirow{2}{*}{ miRNA } & \multicolumn{2}{|c|}{ qPCR } & \multicolumn{2}{|c|}{ ROC } & \multirow{2}{*}{ Target * } & \multirow{2}{*}{ TF } & \multicolumn{4}{|c|}{ miRNA-TF co-regulatory Networks } \\
\hline & $\log F C$ & $p$-value & AUC & $p$-value & & & FBL & miRNA-FFL & TF-FFL & Composite FFL \\
\hline miR-320a & 0.8383653 & 0.0018 & 0.735 & 0.0001 & 157 & 141 & 4 & 6 & 52 & 9 \\
\hline miR-125a-5p & 0.9214846 & 0.0059 & 0.708 & 0.0016 & 140 & 40 & 2 & 9 & 28 & 6 \\
\hline miR-652-3p & 0.5953385 & 0.0078 & 0.701 & 0.0017 & 2 & 5 & & & & \\
\hline miR-185-5p & 0.5878233 & 0.0080 & 0.719 & 0.0002 & 220 & 49 & 1 & 2 & 20 & \\
\hline miR-942-5p & 0.7367637 & 0.0083 & 0.699 & 0.0016 & & 95 & & & & \\
\hline miR-25-3p & 0.5819802 & 0.0124 & 0.689 & 0.0034 & 119 & 79 & 1 & 4 & 52 & 10 \\
\hline
\end{tabular}

Abbreviations: $\mathrm{ROC}=$ receiver operating characteristic; $\mathrm{AUC}=$ area under the receiver operating characteristic; TF $=$ transcription factor; FBL $=$ feedback loop; FFL = feed-forward loop

* Experimentally validated by reporter gene assays or computationally predicted at least by four algorithms. 
A peculiar miRNA-TF co-regulatory network was identified according to three-node feed-forward loops (FFLs): miRNA-FFL, TF-FFL, and composite FFL. The resultant network consisted of 93 nodes and 198 edges (Figure 5).

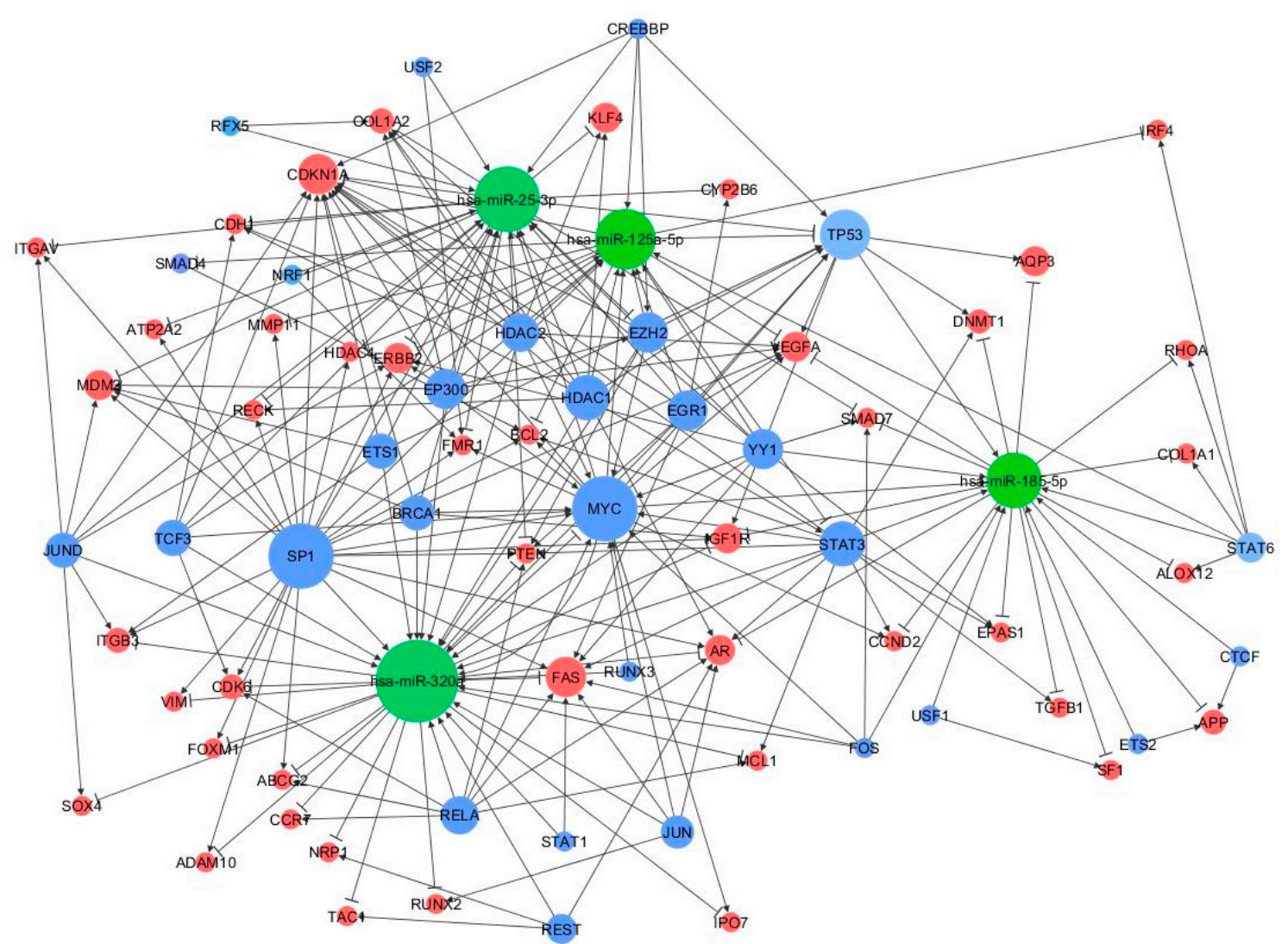

Figure 5. MiRNA-TF co-regulatory network. MiRNAs, genes and TFs are represented in green, red, and blue, respectively. Connections between the main players of the network are depicted by lines where the edges reflect the regulator mechanism, the arrows represent activation, and the perpendicular bars represent repression. The size of node is proportional to the degree of the node, i.e., the number of incoming and outgoing edges.

Among the 198 FFLs, 21 were miRNA-FFLs (with miRNA acting as the main regulator), 152 belong to TF-FFLs (the main regulator here is the TF), and 25 were composite FFLs, where TF and miRNA regulate each other and their mutual targets. The nodes with the largest degree values (i.e., number of connections) were MYC, TP53, CDKN1A, SP1, and STAT3 (55, 47, 40, 36, and 34 edge connections, respectively), suggesting that they might be critical elements in the regulatory process of MS (FFL information are in Supplementary Table S1).

Among the above three subnetworks (miRNA-FFL, TF-FFL, and composite FFL), six genes (BCL2, MCL1, VEGFA, CDH1, CDK6, PTEN), three miRNAs (miR-125a-5p, miR-320a, miR-25-3p) and three TFs (MYC, STAT3, TP53) participated in all of them.

\subsection{Functional Enrichment and Pathway Analysis}

Using the Database for Annotation, Visualization and Integrated Discovery (DAVID) [25] platform, we performed the functional enrichment analysis of all the nodes of the assembled miRNA-TF-based networks. The results showed several significant terms related to immunology, neurology, and inflammation processes (see Supplementary Figure S1 and Supplementary Table S2), e.g., immune system development (ad. $p$-value $\left.=1.6 \times 10^{-11}\right)$, leukocyte differentiation (adj. $p$-value $\left.=2.01 \times 10^{-6}\right)$, leukocyte activation (adj. $p$-value $\left.=1 \times 10^{-3}\right)$, lymphocyte activation (adj. 
$p$-value $\left.=3.5 \times 10^{-3}\right)$, lymphocyte differentiation (adj. $p$-value $\left.=8.29 \times 10^{-6}\right)$, T cell differentiation (adj. $p$-value $\left.=4.71 \times 10^{-4}\right)$, T cell activation $\left(\right.$ adj. $p$-value $\left.=9.7 \times 10^{-3}\right)$, B cell differentiation (adj. $p$-value $\left.=2.3 \times 10^{-3}\right)$, regulation of neurogenesis (adj. $p$-value $\left.=1.07 \times 10^{-6}\right)$, neuron development (adj. $p$-value $=6.07 \times 10^{-4}$ ), and regulation of cytokine production (adj. $p$-value $=1 \times 10^{-3}$ ).

An enrichment pathway analysis was also carried out among the identified hubs (Supplementary Table S3). The most significant were: the neurotrophin signalling pathway (adj. $p$-value $=6.08 \times 10^{-6}$ ), the ErbB signalling pathway (adj. $p$-value $\left.=6.19 \times 10^{-6}\right)$, the adherens junction $\left(\right.$ adj. $p$-value $=7.63 \times 10^{-5}$ ), and the axon guidance (adj. $p$-value $=2.72 \times 10^{-4}$ ) pathways.

\subsection{Target Validation of miR-125a by Dual Luciferase Reporter Assay}

The emerging importance of miR-125a-5p in the pathogenesis of MS led us to validate its predicted target genes related to mechanisms involved in MS. Therefore, in order to verify the ability of miR-125a-5p to post-transcriptionally downregulate putative targets through its binding to specific sites within their 3' UTRs, a Dual Luciferase Reporter Assay was performed. The selected putative target genes assessed by this approach were DIP2A, ADD2, and E2F2.

We found that miR-125a caused a significant reduction of the normalized luciferase expression of DIP2A $\left(39.6 \%, p\right.$-value $\left.=6.8 \times 10^{-4}\right), \operatorname{ADD} 2\left(13.4 \%, p\right.$-value $\left.=3 \times 10^{-4}\right)$, and E2F2 $(21.2 \%, p$-value $=$ $4.9 \times 10^{-3}$ ) with respect to the control miRNA (Figure 6), thus indicating that the selected transcripts can be directly targeted by miR-125a.

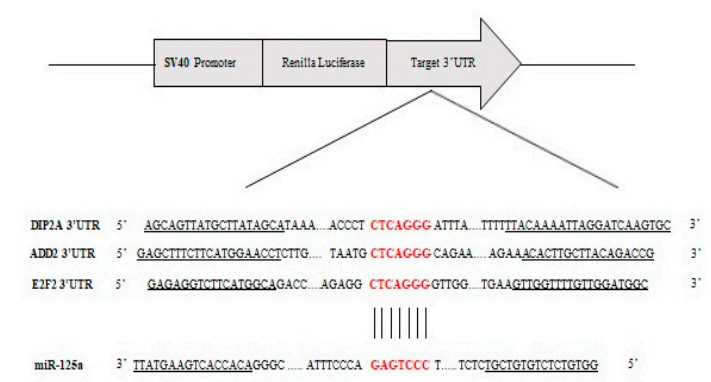

(a)

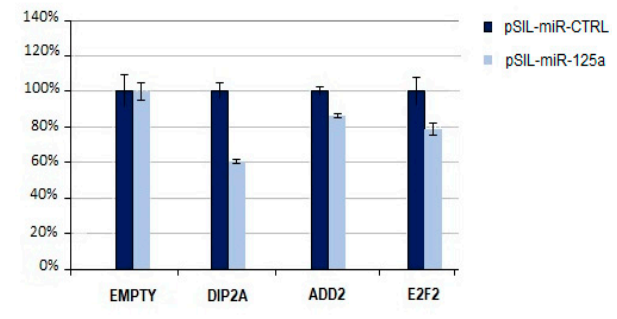

(b)

Figure 6. Experimental validation of miR-125a-5p and its predicted target genes by using luciferase reporter constructs. (a) Schematic representation of the psiCHECK2 luciferase reporter constructs containing the 3'UTR fragments of target genes cloned downstream the Renilla Luciferase gene. The sequence alignment between miR-125a seed region and target genes is reported. (b) The HEK-293T cells were co-transfected with four different experimental designs: (1) psiCHECK2-empty and pSIL-miR-CTRL; (2) psiCHECK2-empty and pSIL-miR-125a; (3) psiCHECK2-3'UTR and pSIL-miR-CTRL; and (4) psiCHECK2-3'UTR and pSIL-miR-125a. Y-axis represents Renilla Luciferase activity (\%) normalized to Firefly Luciferase activity. Data represent the averages of at least three independent experiments with their standard deviations. The $p$-value was calculated by $t$-test. * $p$-value $<0.05$.

\section{Discussion}

Six miRNAs (miR-320a, miR-125a-5p, miR-652-3p, miR-185-5p, miR-942-5p, and miR-25-3p) were significantly upregulated in both pediatric and adult MS patients, suggesting that they may be considered as circulating biomarkers distinctive of the disease, independently from the age of disease onset. Some of these miRNAs (miR-320a, miR-125a-5p, and miR-25-3p) have been already reported as dysregulated in published MS studies [9,25-27], the partial overlap possibly explained, e.g., by differences in the origin of the examined biological samples (blood cells [28-31], brain lesions [32,33], circulating extracellular vesicles [34,35]), or in the method of miRNAs quantification (qPCR, microarray, NGS). The remaining seven miRNAs previously associated with PedMS (let-7a-5p, let-7b-5p, miR-221-3p, miR-182-5p, miR-181a-5p, miR-99b-5p, miR-148b-3p) were not confirmed in 
AOMS, thus requiring a larger sample size to verify whether they were false positives, or more likely, they represent a molecular signature of the very early onset of the disease, in which a minimal environmental influence may enlighten the genetic load of MS [36]. Furthermore, it would be interesting to analyse the significantly DE miRNAs in the peripheral blood samples of patients with other inflammatory and neurodegenerative diseases in order to verify whether they are distinctive of MS rather than associated with common pathogenic pathways.

Among the DE miRNAs, miR-125a-5p was the most frequently associated with MS [9,37-39], and recently it has been implicated in the maturation of oligodendroglia [39]. Furthermore, the level of this miRNA was found abnormally high in cerebrospinal fluid (CSF), blood cells, and brain lesions of MS patients $[40,41]$, suggesting that its pathological upregulation might contribute to the development of MS, leading, e.g., to an impaired repair of the demyelinated lesions. On these grounds, we tested (by luciferase reporter assay) the predicted interactions of miR-125a-5p with three predicted target genes (DIP2A, E2F2, ADD2), all related to mechanisms involved in MS and significantly downregulated in our previous study on PedMS subjects [19]. In our view, the implication of these three genes in the MS pathogenesis seems reasonable. DIP2A regulates both the synapse formation and the axonal path, and its expression was related to the burden of another neurodegenerative disorder, i.e. the Alzheimer's disease [42]. The E2F2 gene was found to be involved in immunologic self-tolerance, the proliferation of autoreactive effector/memory T lymphocytes, and the B-cell differentiation [43,44]. Finally, ADD2 showed interactions with the alpha subunit of the $\mathrm{Na}^{+} / \mathrm{K}^{+}$-ATPase [45], whose dysfunction at the axonal level has been indicated as a major contributor to the progressive neurological decline observed in the chronic phases of MS [46]. Further studies are required to investigate the functional role of these validated miRNA/target regulations. Validations of the remaining genes targeted by the miRNAs of interest are ongoing in order to possibly identify other candidate genetic hubs in the pathogenic network of MS.

Another intriguing opportunity offered by this integrated computational approach was to identify the TF-miRNA co-regulatory networks in the peripheral blood samples of MS patients. SP1, RELA, NF- $\mathrm{KB}, \mathrm{TP} 53, \mathrm{AR}, \mathrm{MYC}, \mathrm{HDAC1}$, and STAT3 were the TFs that regulated 61 miRNA targets and were more frequently connected than other TFs. According to our data, a recently published study showed that the genes RELA, TP53, SP1, HDAC1, and AR seemed to be highly interactive, and demonstrated that a SP1-dependent transcription was able to modulate the autoimmune responses and played a central role in the MS pathogenesis [47]. Interestingly, NF- $\mathrm{KB}$ and STAT3 cooperatively regulate the expression of immune response genes and control the cross-talk between inflammatory and immune cells [48].

On the other hand, MAX, MYC, TCF3, and SREBF1 were TFs in common with the six DE miRNAs of this study. Since they were reported to be implicated in a miRNA-TF co-regulatory axis in prostate cancer [49], in our view it is reasonable to hypothesize that they may act together in the regulation of miRNAs transcription also in other pathological conditions like MS.

Finally, we identified the TF and miRNA mediated regulatory motifs, including FBLs and FFLs, which are promising regulators in MS. The FFL, a three-node motif pattern, is composed of two input elements (TF and miRNA) regulating each other and jointly impacting their target gene [50]. Although TFs and miRNAs seem to cooperate in the framework of a multigene transcriptional and post-transcriptional FFL, as far as we know, this regulatory mechanism has been poorly investigated in MS. In the MS network that was outlined in our analysis, many FFLs were TF-FFLs in which the TFs regulated either the miRNA or the gene; the resultant miRNA-TF co-regulatory network showed some critical hubs associated with MS. In particular, the nodes with the largest degree values were MYC, CDKN1A, TP53, SP1, and STAT3, suggesting that they may be crucial in the regulatory process of MS. Accordingly, Freiesleben et al. [11] identified 107 MS specific FFLs, which involved SP1, CDKN1A, TP53, and miR-125a-5p as critical nodes in the regulatory network motifs of the disease.

Among the other above-mentioned genes, BCL2 was reported as highly expressed in RRMS patients [51], while STAT3, MYC, JUN, NF- $\mathrm{kB}$, and PTEN were identified as candidate genes for the MS 
susceptibility [52]. The study of Kristjansdottir et al. showed that an increased amount of transcription factor SP1 binds the risk allele of the CGGGG indel polymorphism significantly associated with MS [53], whereas TCF3 was found to be implicated in the gene transcription regulation observed in the pathogenic mechanisms of the disease [54]. Therefore, although we performed a computational miRNA-based screening of target genes not necessarily associated with MS, we found that the list of the critical hubs identified in this study was significantly enriched in MS-related genes. In our view, this represents a further support for the computational approach that we have applied, since it is independent from any pre-existing bias of other published MS studies.

Functional studies are needed to validate each segment of the identified hubs (miRNAs, TFs, and their targets); meanwhile, a pathway enrichment analysis was carried out among them in order to possibly identify common affected pathways already associated with MS. The most significant was the neurotrophin signalling pathway that recruited four DE miRNAs (miR-125a-5p, miR-320a, miR-185-5p, and miR-25-3p), 18 miRNA targets, and six TFs (RELA, TP53, NF-kB1, FOXO3, JUN, ABL1), thus confirming the pivotal role of neurotrophin in neuroprotective and neurodegeneration processes of MS [55]. Furthermore, they induce the release of neuroregulins, mediators of their biological activity through the binding of the receptor tyrosine kinases that encloses the ErbB genes [56,57]. The ErbB receptor family is an important regulator of oligodendrogenesis, myelination, and serotonin brain levels [58]; interestingly, we found that the ErbB signalling was the second most significant canonical pathway resulting from our data. On the other hand, a Gene Ontology (GO) term enrichment analysis showed that all the DE miRNAs, TFs, and their target genes were involved in important immune functions and in the maintenance of neuronal homeostasis. For example, miR-125a-5p and its validated target gene ADD2 were found to be implicated in the immune system development; furthermore, miR-125a-5p targeted multiple genes involved in both immunology-related (e.g., T and B cell differentiation) and neurology-related terms (e.g., neuron differentiation and development).

In conclusion, in this study we were able to draw a systematic, comprehensive, and complex predictive network associated with MS, in which some hubs, represented by miRNAs and FFLs, seem to play important roles in the regulatory networks underlying the disease pathogenesis. Since the significant TFs and target genes were not preliminarily selected as associated with MS, we used very stringent bioinformatic criteria to detect the relevant hubs while avoiding false positive outcomes. We applied a computational hypothesis-free, unbiased approach that overcomes the gaps imposed by the incomplete understanding of this complex multifactorial disease. In fact, we believe that restricting the investigation to a pre-selection of only known MS-associated genetic elements might influence the results and provide only a partial view of the disease mechanisms that still remain largely unknown. Further functional analyses are ongoing in order to investigate and clarify the role of the identified hubs in MS pathogenesis.

Above all, our study identified candidate gene regulatory network motifs, which might improve the understanding of gene regulation mechanisms in MS; additionally, a comparison between the molecular profile (miRNA expression) of pediatric and adult MS was performed, revealing some discrepancies that, if confirmed in larger populations, may be the resulting effect, e.g., of environmental factors in the epigenetic components of this complex disease.

\section{Materials and Methods}

\subsection{Study Population}

Caucasian patients with adult onset MS [59,60] were recruited at the Department of Basic Sciences, Neurosciences and Sense Organs, University of Bari (Italy).

Age-matched healthy controls (HCs) were recruited among volunteers who did not show clinical signs or instrumental evidences of inflammatory or neurological diseases, and who had negative family histories for MS and other neurodegenerative diseases. 
All experiments were performed according to relevant guidelines/regulations and approved by the local ethical committee of the Azienda Ospedaliera Policlinico Universitario of Bari (Italy) (prot. 0070059/CE, 18-09-2015). Written informed consent was obtained from all participants (under the Declaration of Helsinki statement).

\subsection{Sample Preparation}

Peripheral blood samples were collected in PAXgene Blood RNA Tubes (PreAnalytiX Qiagen/BD, Hombrechtikon, Switzerland), coded, anonymized, and frozen at $-20^{\circ} \mathrm{C}$.

Total RNA was isolated by using PAXgene Blood RNA Kit (PreAnalytiX Qiagen/BD, Hilden, Germany). RNA purification was performed using the manual procedure, according to the manufacturer's protocol. RNA quantity and quality were assessed by Nanodrop ND-1000 (Thermo Fisher Scientific, Wilmington, DE, USA) and RNA 6000 Pico chip on Bioanalyzer 2100 (Agilent Technologies, Santa Clara, CA, USA), respectively.

\subsection{Reverse Transcription and Microfluidic $q P C R$}

TaqMan Advanced miRNA Cards (Applied Biosystems, Thermo Fisher Scientific) were employed for the quantitative analysis of the 13 miRNA expressions. The input RNA was reverse transcribed using a TaqMan Advanced miRNA cDNA synthesis kit (Applied Biosystems, Thermo Fisher Scientific), and then subjected to qPCR in triplicate using the TaqMan microfluidic cards, according to the manufacturer's protocol. The TaqMan card is a custom designed miRNA assay, preconfigured in a 384-well format and spotted onto a microfluidic card. The card enables the simultaneous quantitation of 13 human miRNAs plus 2 endogenous reference miRNAs for 8 samples per card ( 3 replicates per assay). Briefly, $25 \mu \mathrm{L}$ of diluted pre-amplified product was mixed with $50 \mu \mathrm{L}$ of TaqManVR Fast Advanced Master Mix (Applied Biosystems, Thermo Fisher Scientific) and $25 \mu \mathrm{L}$ of nuclease-free water; $100 \mu \mathrm{L}$ of the PCR reaction mix was dispensed into each port of the TaqMan Advanced miRNA Card. Each card was centrifuged, sealed with a TaqMan low-density array sealer (Applied Biosystems, Life Technologies), and placed in the microfluidic card sample block of an ABI PrismVR 7900HT sequence detection system (Applied Biosystems, Life Technologies). Finally, PCR amplification was performed. Thermal cycling parameters were $10 \mathrm{~min}$ at $92{ }^{\circ} \mathrm{C}$ to enzyme activation, 40 cycles of denaturation at 95 ${ }^{\circ} \mathrm{C}$ for 1 sec, and annealing and extension at $60^{\circ} \mathrm{C}$ for $20 \mathrm{~s}$.

Raw Ct values were calculated using RQ manager software v.2.3 (ABI).

\subsection{Statistical Analysis}

The relative expression levels of each miRNA, normalized to the geometric mean of endogenous reference miRNAs (miR-191-5p and miR-103a-3p), were calculated using the formula $2^{-\Delta \Delta C T}$, as in equation (1), where

$$
\Delta \Delta \mathrm{Ct}=\left(\mathrm{Ct}_{\text {Target }}-\mathrm{Ct}_{\text {References }}\right)_{\mathrm{MS}}-\left(\mathrm{Ct}_{\text {Target }}-\mathrm{Ct}_{\text {References }}\right)_{\text {Calibrator }}
$$

Each sample was replicated three times. The cycle number at which the reaction crossed an arbitrarily placed threshold $(\mathrm{Ct})$ was determined for each miRNA. We used $\mathrm{Ct}=40$ as a cut-off. The Mann-Whitney test was performed to identify differentially expressed miRNAs between MS patients and HC subjects. $p$-value $<0.05$ was considered statistically significant.

The receiver operating characteristic curve (ROC) is a graphical approach for investigating sensitivity and specificity, and the area under ROC (AUC) provides an estimate of the miRNA's ability to discriminate the compared groups. ROC curve analysis was performed, and AUC was calculated using MedCalc Software. The associated $p$-values and AUCs were calculated for each miRNA. 


\subsection{MicroRNA Target Analysis}

Seven databases comprising predicted and validated miRNA-target interactions were used. miRanda (http://www.microrna.org/microrna/home.do, latest access: 08-01-2018), DIANA-microT-CDS [61], rna22 (https:/ / cm.jefferson.edu/rna22, latest access: 08-01-2018), mirDB (http:/ / ophid.utoronto.ca/mirDIP, latest access: 08-01-2018), and TargetScan (http:/ /www.targetscan. org/vert_71, latest access: 11-01-2018) collect predicted miRNA targets. Two databases, miRtarbase (http://mirtarbase.mbc.nctu.edu.tw, latest access: 14-01-2018) and DIANATarbase (http://diana. imis.athena-innovation.gr/DianaTools/index.php?r1/4site/index, latest access: 14-01-2018), contain validated miRNA targets.

In order to reduce the probability of false positives and/or negatives, only those bindings that were confirmed by reporter gene assays in the previously mentioned databases or computationally predicted at least by 4 algorithms were finally selected.

\subsection{Transcription Factor Target Analysis}

TF-miRNA interactions were exported from the CHEA [62], ENCODE [63], TRANSFAC [64], MotifMap [65], and JASPAR [66] datasets obtained from the Harmonizome [24] repository, and combined with information on interactions from TransmiR database [6].

TF-mRNA interactions were exported from the TRRUST v.2 database (www.grnpedia.org/trrust), which makes use of a text-mining algorithm coupled with manual curation of the results to populate a database of 8444 regulatory interactions [67].

Finally, miRNA-TF co-regulatory networks were constructed according to the miRNA-based FFL, TF-based FFL, and miRNA-TF FBLs. These networks were visualized using Cytoscape v3.6.0 [23].

\subsection{Functional and Pathway Analysis}

To identify genes functionally related to miRNA- or TF-based networks, we performed a functional analysis (GO-term) using the Database for Annotation, Visualization and Integrated Discovery (DAVID v6.8, http:/ / david.abcc.ncifcrf.gov, latest access: 16-01-2018) tool. We adjusted the $p$-value of the enriched terms for multiple testing using the Benjamini-Hochberg correction (adjusted $p$-value $<0.05$ ). We also performed a pathway analysis using the DAVID tool and adjusted the $p$-value of the enriched pathway using the Benjamini-Hochberg correction (adjusted $p$-value $<0.05$ ).

\subsection{Luciferase Reporter Assay}

The human HEK-293T cell line, purchased from the American Type Culture Collection (ATCC, MD) was cultured in DMEM/High Glucose medium (Thermo Fisher Scientific) supplemented with $10 \%$ fetal bovine serum (FBS, Thermo Fisher Scientific) and $100 \mathrm{U} / \mathrm{mL}$ penicillin/streptomycin (Thermo Fisher Scientific) in $5 \% \mathrm{CO} 2$ at $37^{\circ} \mathrm{C}$.

To construct luciferase reporter vectors, the $3^{\prime} \mathrm{UTR}$ fragments of target genes containing the miR-125a putative binding site were amplified by PCR using Platinum Taq DNA Polymerase (Thermo Fisher Scientific) and cloned into psiCHECK-2 vector (Promega, Madison, Wisconsin, USA) downstream the Renilla luciferase reporter gene. Primers $\left(5^{\prime}\right.$ to $\left.3^{\prime}\right)$ used for cloning DIP2a were: For GGTCTCGAGCAGTTATGCTTATAGCA and Rev CCAGCGGCCGCACTTGATCCTAATTTTGTAA; primers ( $5^{\prime}$ to $\left.3^{\prime}\right)$ used for cloning ADD2 were: For GCTCTCGAGCTTTCTTCATGGAACCT and Rev CGTGCGGCCGCGGTCTGTAAGCAAGTGT; primers ( $5^{\prime}$ to $\left.3^{\prime}\right)$ used for cloning E2F2 were: For GGACTCGAGAGGTCTTCATGGCA and Rev GGAGCGGCCGCCATCCAACAAAACCAAC. The vectors were obtained cloning PCR products into psiCHECK-2 plasmid using XhoI and NotI restriction enzymes.

To construct the miR-125a expression plasmid, the pre-miR-125a and its flanking regions were obtained by PCR amplification using Platinum Taq DNA Polymerase (Thermo Fisher Scientific) and cloned into pSilencer (pSIL) 4.1-CMV neo vector (Thermo Fisher Scientific). Primers ( $5^{\prime}$ to $\left.3^{\prime}\right)$ used for 
cloning miR-125a were: For TCTCTGCTGTGTCTCTGTGG and Rev TTATGAAGTCACCACAGGGC. The vectors were obtained by cloning PCR products into psiCHECK-2 plasmid using BamHI and HindIII restriction enzymes. Plasmid construct sequences were verified by Sanger sequencing.

Lipofectamine 2000 (Invitrogen, Thermo Fisher Scientific) was used for transfection following manufacturer's instructions. Briefly, $\sim 10,000$ cells per well in 24 -well plates were transfected with a mixture including $100 \mathrm{ng}$ psiCHECK2-3'UTR construct and $300 \mathrm{ng}$ pSIL-miR125a construct; for controls, $100 \mathrm{ng}$ of psiCHECK2-empty (control vector without any cloned region) construct and $300 \mathrm{ng}$ pSIL-miR-CTRL were used. Each transfection was repeated in triplicate. The dual-luciferase assays (Promega) were performed at $48 \mathrm{~h}$ after transfection and luminescence was measured using a Victor Light 1420 luminometer (Perkin Elmer).

The ratio (R/FF) of Renilla luciferase activity to Firefly luciferase activity (used as an internal control of the transfection efficiency) in each well was normalized to the average ratio of the control wells in each plate in which the ratio was designated as 1 . All experimental data are presented as the mean \pm SD from three independent transfection experiments. Statistical analysis was performed by Two-tailed Student's $t$-tests and a $p$-value $<0.05$ was considered statistically significant.

Supplementary Materials: Supplementary materials can be found at http:/ /www.mdpi.com/1422-0067/19/11/ 3652/s1.

Author Contributions: Design of the study, M.L., N.N.; Formal analysis, N.N., A.C. and S.L.; investigation, N.N. and M.L.; validation, N.N., L.V. and P.P.; methodology, N.N., L.V., P.P. and A.C.; software, A.C.; data curation, M.L., S.L. and M.T.; funding acquisition, M.L.; writing-original Draft, N.N. and M.L.; writing-review and editing, M.L.

Funding: This work was supported by Fondazione Italiana Sclerosi Multipla (FISM) Grant no. 2014/R/10.

Acknowledgments: The authors would like to thank the MS patients and controls who kindly participated in this project. They also wish to thank Ileana Zucchi for supporting the study, and Giuseppe Cananzi for technical support.

Conflicts of Interest: The authors declare no conflict of interest. The funders had no role in the design of the study, in the collection, analyses, or interpretation of data, in the writing of the manuscript, or in the decision to publish the results.

\section{Abbreviations}

$\begin{array}{ll}\text { miRNA } & \text { microRNA } \\ \text { TF } & \text { Transcription Factor } \\ \text { MS } & \text { Multiple Sclerosis } \\ \text { PedMS } & \text { Pediatric Multiple Sclerosis } \\ \text { AOMS } & \text { Adult-Onset Multiple Sclerosis } \\ \text { FBL } & \text { Feedback Loop } \\ \text { FFL } & \text { Feed-Forward Loop } \\ \text { CNS } & \text { Central Nervous System } \\ \text { HC } & \text { Healthy Control } \\ \text { DE } & \text { Differentially Expressed } \\ \text { ROC } & \text { Receiver Operating Characteristic } \\ \text { AUC } & \text { Area Under the Curve } \\ \text { R } & \text { Renilla } \\ \text { FF } & \text { Firefly }\end{array}$

\section{References}

1. Bartel, D.P. MicroRNAs: Genomics, Biogenesis, Mechanism, and Function. Cell 2004, 116, 281-297. [CrossRef]

2. Kozomara, A.; Griffiths-Jones, S. miRBase: Annotating high confidence microRNAs using deep sequencing data. Nucleic Acids Res. 2013, 42, D68-D73. [CrossRef] [PubMed]

3. Na, Y.-J.; Kim, J.H. Understanding cooperativity of microRNAs via microRNA association networks. BMC Genomics 2013, 14, S17. [CrossRef] [PubMed] 
4. Su, W.-L.; Kleinhanz, R.R.; Schadt, E.E. Characterizing the role of miRNAs within gene regulatory networks using integrative genomics techniques. Mol. Syst. Biol. 2011, 7, 490. [CrossRef] [PubMed]

5. Hashimoto, Y.; Akiyama, Y.; Yuasa, Y. Multiple-to-multiple relationships between microRNAs and target genes in gastric cancer. PLoS ONE 2013, 8, e62589. [CrossRef] [PubMed]

6. Wang, J.; Lu, M.; Qiu, C.; Cui, Q. TransmiR: A transcription factor-microRNA regulation database. Nucleic Acids Res. 2009, 38, D119-D122. [CrossRef] [PubMed]

7. Sadeghi, M.; Ranjbar, B.; Ganjalikhany, M.R.; Khan, F.M.; Schmitz, U.; Wolkenhauer, O.; Gupta, S.K. MicroRNA and transcription factor gene regulatory network analysis reveals key regulatory elements associated with prostate cancer progression. PLOS ONE 2016, 11, e0168760. [CrossRef] [PubMed]

8. Wang, H.; Luo, J.; Liu, C.; Niu, H.; Wang, J.; Liu, Q.; Zhao, Z.; Xu, H.; Ding, Y.; Sun, J. Investigating MicroRNA and transcription factor co-regulatory networks in colorectal cancer. BMC Bioinform. 2017, 18, 388. [CrossRef] [PubMed]

9. Zhang, H.-M.; Kuang, S.; Xiong, X.; Gao, T.; Liu, C.; Guo, A.-Y. Transcription factor and microRNA co-regulatory loops: Important regulatory motifs in biological processes and diseases. Brief. Bioinform. 2013, 16, 45-58. [CrossRef] [PubMed]

10. Zhang, G.; Shi, H.; Wang, L.; Zhou, M.; Wang, Z.; Liu, X.; Cheng, L.; Li, W.; Li, X. MicroRNA and Transcription Factor Mediated Regulatory Network Analysis Reveals Critical Regulators and Regulatory Modules in Myocardial Infarction. PLoS ONE 2015, 10, e0135339. [CrossRef] [PubMed]

11. Freiesleben, S.; Hecker, M.; Zettl, U.K.; Fuellen, G.; Taher, L. Analysis of microRNA and gene expression profiles in multiple sclerosis: Integrating interaction data to uncover regulatory mechanisms. Sci. Rep. 2016, 6, 34512. [CrossRef] [PubMed]

12. Smith, K.M.; Guerau-de-Arellano, M.; Costinean, S.; Williams, J.L.; Bottoni, A.; Cox, G.M.; Satoskar, A.R.; Croce, C.M.; Racke, M.K.; Lovett-Racke, A.E. miR-29ab1 deficiency identifies a negative feedback loop controlling Th1 bias that is dysregulated in multiple sclerosis. J. Immunol. 2012, 1103171. [CrossRef] [PubMed]

13. Vermersch, P.; Berger, T.; Gold, R.; Lukas, C.; Rovira, A.; Meesen, B.; Chard, D.; Comabella, M.; Palace, J.; Trojano, M. The clinical perspective: How to personalise treatment in MS and how may biomarkers including imaging contribute to this? Mult. Scler. 2016, 22, 18-33. [CrossRef] [PubMed]

14. Oksenberg, J.R.; Baranzini, S.E. Multiple sclerosis genetics-is the glass half full, or half empty? Nat. Rev. Neurol. 2010, 6, 429-437. [CrossRef] [PubMed]

15. Chitnis, T.; Glanz, B.; Jaffin, S.; Healy, B. Demographics of pediatric-onset multiple sclerosis in an MS center population from the Northeastern United States. Mult. Scler. J. 2009, 15, 627-631. [CrossRef] [PubMed]

16. Banwell, B.; Krupp, L.; Kennedy, J.; Tellier, R.; Tenembaum, S.; Ness, J.; Belman, A.; Boiko, A.; Bykova, O.; Waubant, E. Clinical features and viral serologies in children with multiple sclerosis: A multinational observational study. Lancet Neurol. 2007, 6, 773-781. [CrossRef]

17. Ghezzi, A.; Pozzilli, C.; Liguori, M.; Marrosu, M.G.; Milani, N.; Milanese, C.; Simone, I.; Zaffaroni, M. Prospective study of multiple sclerosis with early onset. Mult. Scler. J. 2002, 8, 115-118. [CrossRef] [PubMed]

18. Barnett, M.H.; Parratt, J.D.E.; Pollard, J.D.; Prineas, J.W. MS: Is it one disease? Int. MS J. 2009, 16, 57-65. [PubMed]

19. Liguori, M.; Nuzziello, N.; Licciulli, F.; Consiglio, A.; Simone, M.; Viterbo, R.G.; Creanza, T.M.; Ancona, N.; Tortorella, C.; Margari, L. Combined microRNA and mRNA expression analysis in pediatric multiple sclerosis: An integrated approach to uncover novel pathogenic mechanisms of the disease. Hum. Mol. Genet. 2017, 27, 66-79. [CrossRef] [PubMed]

20. Punga, T.; Bartoccioni, E.; Lewandowska, M.; Damato, V.; Evoli, A.; Punga, A.R. Disease specific enrichment of circulating let-7 family microRNA in MuSK+ myasthenia gravis. J. Neuroimmunol. 2016, 292, 21-26. [CrossRef] [PubMed]

21. Mancuso, R.; Hernis, A.; Agostini, S.; Rovaris, M.; Caputo, D.; Clerici, M. MicroRNA-572 expression in multiple sclerosis patients with different patterns of clinical progression. J. Transl. Med. 2015, 13, 148. [CrossRef] [PubMed]

22. Bossel Ben-Moshe, N.; Avraham, R.; Kedmi, M.; Zeisel, A.; Yitzhaky, A.; Yarden, Y.; Domany, E. Context-specific microRNA analysis: Identification of functional microRNAs and their mRNA targets. Nucleic Acids Res. 2012, 40, 10614-10627. [CrossRef] [PubMed] 
23. Shannon, P.; Markiel, A.; Ozier, O.; Baliga, N.S.; Wang, J.T.; Ramage, D.; Amin, N.; Schwikowski, B.; Ideker, T. Cytoscape: A software environment for integrated models of biomolecular interaction networks. Genome Res. 2003, 13, 2498-2504. [CrossRef] [PubMed]

24. Rouillard, A.D.; Gundersen, G.W.; Fernandez, N.F.; Wang, Z.; Monteiro, C.D.; McDermott, M.G.; Ma'ayan, A. The harmonizome: A collection of processed datasets gathered to serve and mine knowledge about genes and proteins. Database 2016, 2016. [CrossRef] [PubMed]

25. Huang, D.W.; Sherman, B.T.; Lempicki, R.A. Systematic and integrative analysis of large gene lists using DAVID bioinformatics resources. Nat. Protoc. 2008, 4, 44. [CrossRef] [PubMed]

26. Regev, K.; Paul, A.; Healy, B.; von Glenn, F.; Diaz-Cruz, C.; Gholipour, T.; Mazzola, M.A.; Raheja, R.; Nejad, P.; Glanz, B.I. Comprehensive evaluation of serum microRNAs as biomarkers in multiple sclerosis. Neurol. Neuroimmunol. Neuroinflamm. 2016, 3, e267. [CrossRef] [PubMed]

27. Keller, A.; Leidinger, P.; Steinmeyer, F.; Stähler, C.; Franke, A.; Hemmrich-Stanisak, G.; Kappel, A.; Wright, I.; Dörr, J.; Paul, F. Comprehensive analysis of microRNA profiles in multiple sclerosis including next-generation sequencing. Mult. Scler. J. 2014, 20, 295-303. [CrossRef] [PubMed]

28. Muñoz-Culla, M.; Irizar, H.; Sáenz-Cuesta, M.; Castillo-Triviño, T.; Osorio-Querejeta, I.; Sepúlveda, L.; De Munain, A.L.; Olascoaga, J.; Otaegui, D. SncRNA (microRNA \& snoRNA) opposite expression pattern found in multiple sclerosis relapse and remission is sex dependent. Sci. Rep. 2016, 6, 20126. [PubMed]

29. Sievers, C.; Meira, M.; Hoffmann, F.; Fontoura, P.; Kappos, L.; Lindberg, R.L. Altered microRNA expression in B lymphocytes in multiple sclerosis: Towards a better understanding of treatment effects. Clin. Immunol. 2012, 144, 70-79. [CrossRef] [PubMed]

30. De Santis, G.; Ferracin, M.; Biondani, A.; Caniatti, L.; Rosaria Tola, M.; Castellazzi, M.; Zagatti, B.; Battistini, L.; Borsellino, G.; Fainardi, E.; et al. Altered miRNA expression in T regulatory cells in course of multiple sclerosis. J. Neuroimmunol. 2010, 226, 165-171. [CrossRef] [PubMed]

31. Otaegui, D.; Baranzini, S.E.; Armañanzas, R.; Calvo, B.; Muñoz-Culla, M.; Khankhanian, P.; Inza, I.; Lozano, J.A.; Castillo-Triviño, T.; Asensio, A. Differential micro RNA expression in PBMC from multiple sclerosis patients. PLoS ONE 2009, 4, e6309. [CrossRef] [PubMed]

32. Junker, A.; Krumbholz, M.; Eisele, S.; Mohan, H.; Augstein, F.; Bittner, R.; Lassmann, H.; Wekerle, H.; Hohlfeld, R.; Meinl, E. MicroRNA profiling of multiple sclerosis lesions identifies modulators of the regulatory protein CD47. Brain 2009, 132, 3342-3352. [CrossRef] [PubMed]

33. Dutta, R.; Chomyk, A.M.; Chang, A.; Ribaudo, M.V.; Deckard, S.A.; Doud, M.K.; Edberg, D.D.; Bai, B.; Li, M.; Baranzini, S.E.; et al. Hippocampal demyelination and memory dysfunction are associated with increased levels of the neuronal microRNA miR-124 and reduced AMPA receptors. Ann. Neurol. 2013, 73, 637-675. [CrossRef] [PubMed]

34. Selmaj, I.; Mycko, M.P.; Raine, C.S.; Selmaj, K.W. The role of exosomes in CNS inflammation and their involvement in multiple sclerosis. J. Neuroimmunol. 2017, 306, 1-10. [CrossRef] [PubMed]

35. Ebrahimkhani, S.; Vafaee, F.; Young, P.E.; Hur, S.S.; Hawke, S.; Devenney, E.; Beadnall, H.; Barnett, M.H.; Suter, C.M.; Buckland, M.E. Exosomal microRNA signatures in multiple sclerosis reflect disease status. Sci. Rep. 2017, 7, 14293. [CrossRef] [PubMed]

36. Vargas-Lowy, D.; Chitnis, T. Pathogenesis of pediatric multiple sclerosis. J. Child Neurol. 2012, 27, $1394-1407$. [CrossRef] [PubMed]

37. Ma, X.; Zhou, J.; Zhong, Y.; Jiang, L.; Mu, P.; Li, Y.; Singh, N.; Nagarkatti, M.; Nagarkatti, P. Expression, regulation and function of microRNAs in multiple sclerosis. Int. J. Med. Sci. 2014, 11, 810. [CrossRef] [PubMed]

38. Wu, T.; Chen, G. miRNAs participate in MS pathological processes and its therapeutic response. Mediators Inflamm. 2016, 2016, 4578230. [CrossRef] [PubMed]

39. Lecca, D.; Marangon, D.; Coppolino, G.T.; Méndez, A.M.; Finardi, A.; Dalla Costa, G.; Martinelli, V.; Furlan, R.; Abbracchio, M.P. MiR-125a-3p timely inhibits oligodendroglial maturation and is pathologically up-regulated in human multiple sclerosis. Sci. Rep. 2016, 6, 34503. [CrossRef] [PubMed]

40. Yang, D.; Wang, W.-Z.; Zhang, X.-M.; Yue, H.; Li, B.; Lin, L.; Fu, J. MicroRNA expression aberration in Chinese patients with relapsing remitting multiple sclerosis. J. Mol. Neurosci. 2014, 52, 131-137. [CrossRef] [PubMed] 
41. Reijerkerk, A.; Lopez-Ramirez, M.A.; van Het Hof, B.; Drexhage, J.A.; Kamphuis, W.W.; Kooij, G.; Vos, J.B.; van der Pouw Kraan, T.C.; van Zonneveld, A.J.; Horrevoets, A.J. MicroRNAs regulate human brain endothelial cell-barrier function in inflammation: Implications for multiple sclerosis. J. Neurosci. 2013, 33, 6857-6863. [CrossRef] [PubMed]

42. De Jager, P.L.; Srivastava, G.; Lunnon, K.; Burgess, J.; Schalkwyk, L.C.; Yu, L.; Eaton, M.L.; Keenan, B.T.; Ernst, J.; McCabe, C. Alzheimer's disease: Early alterations in brain DNA methylation at ANK1, BIN1, RHBDF2 and other loci. Nat. Neurosci. 2014, 17, 1156. [CrossRef] [PubMed]

43. Murga, M.; Fernández-Capetillo, O.; Field, S.J.; Moreno, B.; Luis, R.; Fujiwara, Y.; Balomenos, D.; Vicario, A.; Carrera, A.C.; Orkin, S.H. Mutation of E2F2 in mice causes enhanced T lymphocyte proliferation, leading to the development of autoimmunity. Immunity 2001, 15, 959-970. [CrossRef]

44. Zhu, J.W.; Field, S.J.; Gore, L.; Thompson, M.; Yang, H.; Fujiwara, Y.; Cardiff, R.D.; Greenberg, M.; Orkin, S.H.; DeGregori, J. E2F1 and E2F2 determine thresholds for antigen-induced T-cell proliferation and suppress tumorigenesis. Mol. Cell. Biol. 2001, 21, 8547-8564. [CrossRef] [PubMed]

45. Krieger, C.; Wang, S.J.H.; Yoo, S.H.; Harden, N. Adducin at the neuromuscular junction in amyotrophic lateral sclerosis: Hanging on for dear life. Front. Cell. Neurosci. 2016, 10, 11. [CrossRef] [PubMed]

46. Young, E.A.; Fowler, C.D.; Kidd, G.J.; Chang, A.; Rudick, R.; Fisher, E.; Trapp, B.D. Imaging correlates of decreased axonal $\mathrm{Na}^{+} / \mathrm{K}^{+}$ATPase in chronic multiple sclerosis lesions. Ann. Neurol. 2008, 63, 428-435. [CrossRef] [PubMed]

47. Menon, R.; Di Dario, M.; Cordiglieri, C.; Musio, S.; La Mantia, L.; Milanese, C.; Di Stefano, A.L.; Crabbio, M.; Franciotta, D.; Bergamaschi, R. Gender-based blood transcriptomes and interactomes in multiple sclerosis: Involvement of SP1 dependent gene transcription. J. Autoimmun. 2012, 38, J144-J155. [CrossRef] [PubMed]

48. Grivennikov, S.I.; Karin, M. Dangerous liaisons: STAT3 and NF- $\mathrm{kB}$ collaboration and crosstalk in cancer. Cytokine Growth Factor Rev. 2010, 21, 11-19. [CrossRef] [PubMed]

49. Pashaei, E.; Pashaei, E.; Ahmady, M.; Ozen, M.; Aydin, N. Meta-analysis of miRNA expression profiles for prostate cancer recurrence following radical prostatectomy. PLoS ONE 2017, 12, e0179543. [CrossRef] [PubMed]

50. Wu, Q.; Qin, H.; Zhao, Q.; He, X.-X. Emerging role of transcription factor-microRNA-target gene feed-forward loops in cancer. Biomed. Rep. 2015, 3, 611-616. [CrossRef] [PubMed]

51. Zettl, U.K.; Kuhlmann, T.; Brück, W. Bcl-2 expressing T lymphocytes in multiple sclerosis lesions. Neuropathol. Appl. Neurobiol. 1998, 24, 202-208. [CrossRef] [PubMed]

52. Luo, D.; Fu, J. Identifying characteristic miRNAs-genes and risk pathways of multiple sclerosis based on bioinformatics analysis. Oncotarget 2018, 9, 5287. [CrossRef] [PubMed]

53. Kristjansdottir, G.; Sandling, J.K.; Bonetti, A.; Roos, I.M.; Milani, L.; Wang, C.; Gustafsdottir, S.M.; Sigurdsson, S.; Lundmark, A.; Tienari, P.J. Interferon regulatory factor 5 (IRF5) gene variants are associated with multiple sclerosis in three distinct populations. J. Med. Genet. 2008, 45, 362-369. [CrossRef] [PubMed]

54. Agirrezabal, I.; Palacios, R.; Moreno, B.; Sepulcre, J.; Abernathy, A.; Saiz, A.; Llufriu, S.; Comabella, M.; Montalban, X.; Martinez, A. Increased expression of dedicator-cytokinesis-10, caspase-2 and Synaptotagmin-like 2 is associated with clinical disease activity in multiple sclerosis. Mult. Scler. Demyelinating Disord. 2016, 1, 7. [CrossRef]

55. Kalinowska-Lyszczarz, A.; Losy, J. The role of neurotrophins in multiple sclerosis-pathological and clinical implications. Int. J. Mol. Sci. 2012, 13, 13713-13725. [CrossRef] [PubMed]

56. Esper, R.M.; Loeb, J.A. Neurotrophins induce neuregulin release through protein kinase C $\delta$ activation. J. Biol. Chem. 2009, 284, 26251-26260. [CrossRef] [PubMed]

57. Mencel, M.; Nash, M.; Jacobson, C. Neuregulin upregulates microglial $\alpha 7$ nicotinic acetylcholine receptor expression in immortalized cell lines: Implications for regulating neuroinflammation. PLOS ONE 2013, 8, e70338. [CrossRef] [PubMed]

58. Chen, J.; He, W.; Hu, X.; Shen, Y.; Cao, J.; Wei, Z.; Luan, Y.; He, L.; Jiang, F.; Tao, Y. A role for ErbB signaling in the induction of reactive astrogliosis. Cell Dis. 2017, 3, 17044. [CrossRef] [PubMed]

59. Polman, C.H.; Reingold, S.C.; Banwell, B.; Clanet, M.; Cohen, J.A.; Filippi, M.; Fujihara, K.; Havrdova, E.; Hutchinson, M.; Kappos, L. Diagnostic criteria for multiple sclerosis: 2010 revisions to the McDonald criteria. Ann. Neurol. 2011, 69, 292-302. [CrossRef] [PubMed] 
60. Thompson, A.J.; Banwell, B.L.; Barkhof, F.; Carroll, W.M.; Coetzee, T.; Comi, G.; Correale, J.; Fazekas, F.; Filippi, M.; Freedman, M.S. Diagnosis of multiple sclerosis: 2017 revisions of the McDonald criteria. Lancet Neurol. 2018, 17, 162-173. [CrossRef]

61. Paraskevopoulou, M.D.; Georgakilas, G.; Kostoulas, N.; Vlachos, I.S.; Vergoulis, T.; Reczko, M.; Filippidis, C.; Dalamagas, T.; Hatzigeorgiou, A.G. DIANA-microT web server v5.0: Service integration into miRNA functional analysis workflows. Nucleic Acids Res. 2013, 41, W169-W173. [CrossRef] [PubMed]

62. Lachmann, A.; Xu, H.; Krishnan, J.; Berger, S.I.; Mazloom, A.R.; Ma'ayan, A. ChEA: Transcription factor regulation inferred from integrating genome-wide ChIP-X experiments. Bioinformatics 2010, 26, 2438-2444. [CrossRef] [PubMed]

63. Consortium, E.P. An integrated encyclopedia of DNA elements in the human genome. Nature 2012, $489,57$. [CrossRef] [PubMed]

64. Matys, V.; Kel-Margoulis, O.V.; Fricke, E.; Liebich, I.; Land, S.; Barre-Dirrie, A.; Reuter, I.; Chekmenev, D.; Krull, M.; Hornischer, K. TRANSFAC ${ }^{\circledR}$ and its module TRANSCompel ${ }^{\circledR}$ : Transcriptional gene regulation in eukaryotes. Nucleic Acids Res. 2006, 34, D108-D110. [CrossRef] [PubMed]

65. Daily, K.; Patel, V.R.; Rigor, P.; Xie, X.; Baldi, P. MotifMap: Integrative genome-wide maps of regulatory motif sites for model species. BMC Bioinformatics 2011, 12, 495. [CrossRef] [PubMed]

66. Khan, A.; Fornes, O.; Stigliani, A.; Gheorghe, M.; Castro-Mondragon, J.A.; van der Lee, R.; Bessy, A.; Cheneby, J.; Kulkarni, S.R.; Tan, G. JASPAR 2018: Update of the open-access database of transcription factor binding profiles and its web framework. Nucleic Acids Res. 2017, 46, D260-D266. [CrossRef] [PubMed]

67. Han, H.; Cho, J.-W.; Lee, S.; Yun, A.; Kim, H.; Bae, D.; Yang, S.; Kim, C.Y.; Lee, M.; Kim, E. TRRUST v2: An expanded reference database of human and mouse transcriptional regulatory interactions. Nucleic Acids Res. 2017, 46, D380-D386. [CrossRef] [PubMed]

(C) 2018 by the authors. Licensee MDPI, Basel, Switzerland. This article is an open access article distributed under the terms and conditions of the Creative Commons Attribution (CC BY) license (http://creativecommons.org/licenses/by/4.0/). 